\title{
Erratum to: Managing Element Interactivity in Equation Solving
}

\author{
Bing Hiong Ngu ${ }^{1} \cdot$ Huy P. Phan ${ }^{1}$ • \\ Alexander Seeshing Yeung ${ }^{2} \cdot$ Siu Fung Chung ${ }^{3}$
}

Published online: 24 February 2017

(C) Springer Science+Business Media New York 2017

\section{Erratum to: Educ Psychol Rev (2016) \\ DOI 10.1007/s10648-016-9397-8}

The original version of this article unfortunately contained mistakes. Alignment of Tables 1 and 3 entries were incorrect. The original article was corrected.

The online version of the original article can be found at http://dx.doi.org/10.1007/s10648-016-9397-8.

\section{Bing Hiong Ngu}

bngu@une.edu.au

1 School of Education, University of New England, Armidale, NSW 2351, Australia

2 Australian Catholic University, Strathfield, Australia

3 Kiang Wu Nursing College of Macau, Macau, China 